\title{
Not If, but When: Autonomous Driving and the Future of Transit
}

\author{
Jerome M. Lutin \\ Independent Consultant
}

\begin{abstract}
This paper discusses the implications of autonomous vehicle technology on auto use and travel behavior, and the resulting impacts on public transportation. The paper goes on to explore how autonomous driving technology can make more efficient use of bus transportation and improve service to disabled individuals. The paper concludes with recommendations for transit agencies to engage with government and suppliers of autonomous vehicles to promote research, development, and policies that will allow the industry to reap the benefits of this revolutionary and disruptive technology.
\end{abstract}

\section{Not If, but When}

The title of a 2014 IHS Automotive report on the market penetration of self-driving cars includes the phrase "not if, but when" (Juliussen and Carlson 2014). Those words epitomize the considerable discourse among scholars, planners, and the media on the future of autonomous vehicles. Since Google announced in 2010 that it had been testing a fleet of autonomous cars, other automakers and researchers have stepped up efforts to promote autonomous driving and driver assist technologies (Thrun 2010). There is, however, considerable speculation and debate on how long it will take for autonomous vehicles to be a major factor for the transit planning community.

Transit is an inherently conservative industry and change is tough when your customers judge your performance mainly on your ability to deliver the same service perfectly day after day without disruption. Consequently the typical course is to ignore change as long as possible. However, it is no longer possible for transit to ignore autonomous driving technology. The future is here now. And this disruptive technology will have significant and long-lasting impacts on the industry. As this paper was being written, Tesla was advertising the availability of "full self-driving capability" on its 2017 passenger cars.

(C) 2018 Jerome M. Lutin

http//dx.doi.org/10.5038/2375-0901.21.1.10

ISSN: 1077-291X | Licenced under Creative Commons License Attribution - Noncommercial 4.0

The Journal of Public Transportation is published by the Center for Urban Transportation Research at the University of South Florida 


\begin{abstract}
All you will need to do is get in and tell your car where to go. If you don't say anything, the car will look at your calendar and take you there as the assumed destination or just home if nothing is on the calendar. Your Tesla will figure out the optimal route, navigate urban streets (even without lane markings), manage complex intersections with traffic lights, stop signs and roundabouts, and handle densely packed freeways with cars moving at high speed. When you arrive at your destination, simply step out at the entrance and your car will enter park seek mode, automatically search for a spot, and park itself. A tap on your phone summons it back to you. (Tesla 2017)
\end{abstract}

Tesla, however, includes the caveat "that Self-Driving functionality is dependent upon extensive software validation and regulatory approval, which may vary widely by jurisdiction" (Tesla 2017). Cadillac is offering a similar hands-free driving system option for its 2018 CT6 line. While current offerings from Tesla and Cadillac are expensive luxury vehicles, Tesla is producing the midrange $\$ 35,000$ Model 3 , which will have the self-driving features. Other automakers will follow with autonomous driving at affordable prices.

For the transit industry, the European Union's CityMobil2 project led the way to autonomous transit by successfully demonstrating automated low-speed $(10 \mathrm{~km} / \mathrm{h})$ transit vehicles in seven European cities, carrying more than 60,000 passengers, and sharing the infrastructure with other road users (CityMobil2 2015). CityMobil2 produced a YouTube video of a demonstration in Trikala, Greece (shown in Figure 1), which foretells one likely future for public transit operation (CityMobil2 2017). An "official driver" sits at a desk remotely overseeing autonomous transit vehicles. Many local jurisdictions in the United States are undertaking demonstrations of low-speed, 10-12 passenger autonomous vehicles based on the EasyMile vehicle developed for CityMobil2.

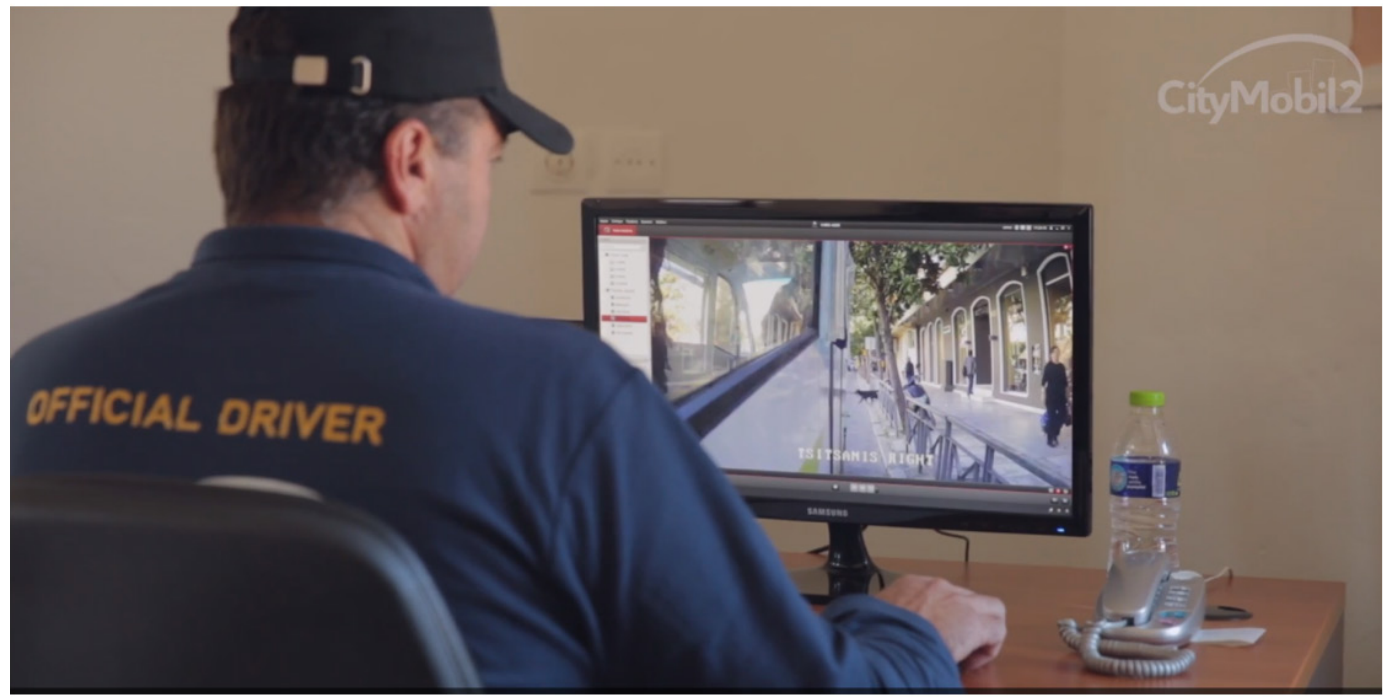

FIGURE 1.

Trikala, Greece, Bus Driver Telecommutes to Work (CityMobil2 2017) 
Autonomous vehicles are becoming part of the transit planning process. During the past 50 years, transit planners were able to assume that travel choices would be limited to modes with familiar characteristics, such as rail and autos. Model parameters could be calibrated using survey data obtained from users of those modes. Today, however, transit planners are faced with an unprecedented change in the way on-road vehicles will be used when they become autonomous. Planners must find ways to properly characterize autonomous vehicles and include them in the spectrum of mode choices available to travelers when confronted with alternative choices.

\section{Definitions of Autonomous Driving Capabilities}

In the Federal Automated Vehicles Policy released in September 2016, the U.S. Department of Transportation (USDOT) changed its original five levels of automation (0 to 4) to correspond with the six levels developed by SAE International, which are similar to those developed by the German Federal Highway Research Institute (BASt). The Policy defines the six levels of automation as follows:

- At SAE Level 0, the human driver does everything;

- At SAE Level 1, an automated system on the vehicle can sometimes assist the human driver conduct some parts of the driving task [i.e., anti-skid braking (ABS) and electronic traction control (ETC)];

- At SAE Level 2, an automated system on the vehicle can actually conduct some parts of the driving task, while the human continues to monitor the driving environment and performs the rest of the driving task [i.e., adaptive cruise control and lane-keeping assist];

- At SAE Level 3, an automated system can both actually conduct some parts of the driving task and monitor the driving environment in some instances, but the human driver must be ready to take back control when the automated system requests [Tesla Autopilot is an example];

- At SAE Level 4, an automated system can conduct the driving task and monitor the driving environment, and the human need not take back control, but the automated system can operate only in certain environments and under certain conditions [i.e., Google and Uber retrofitted vehicles]; and

- At SAE Level 5, the automated system can perform all driving tasks, under all conditions that a human driver could perform them [i.e., the EasyMile vehicle shown in Figure 2, which has no steering wheel, accelerator, or brake pedal]. (USDOT 2016) 


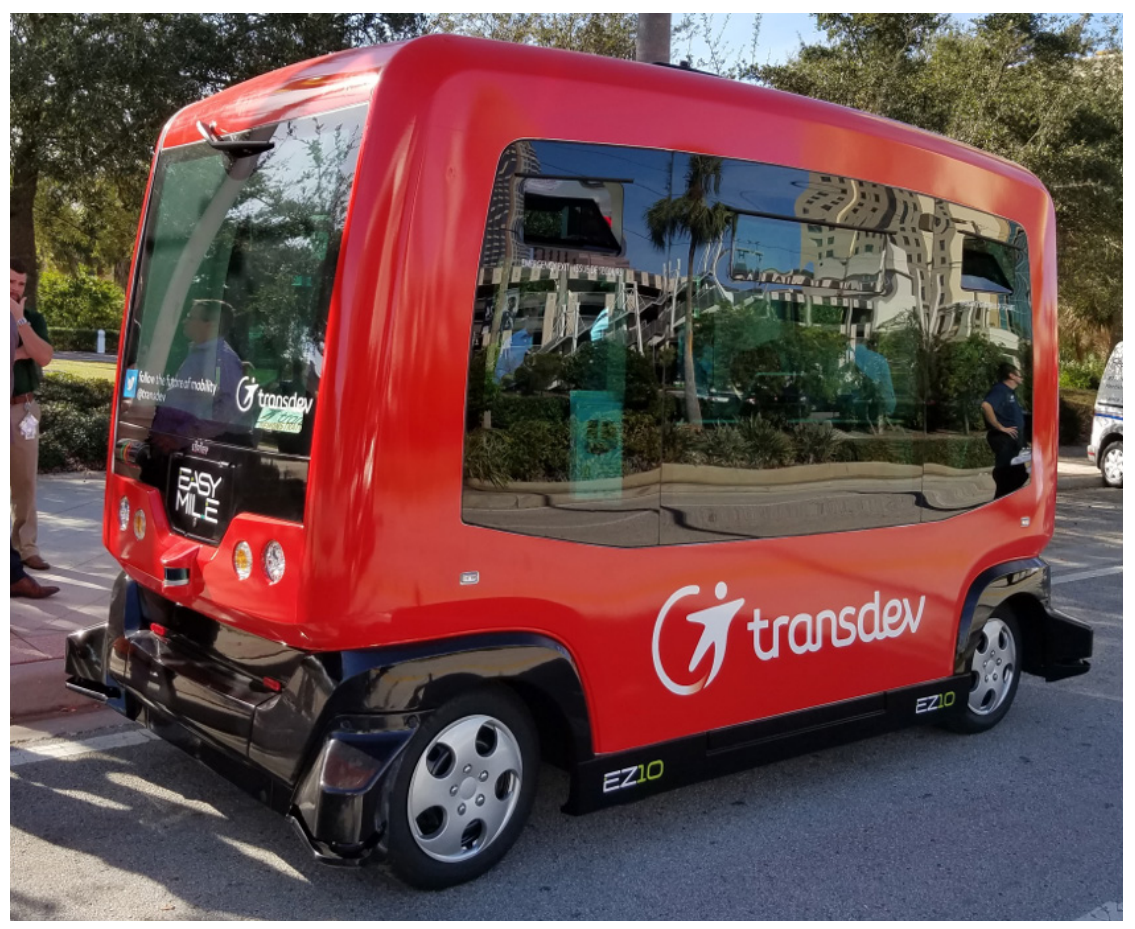

\section{FIGURE 2.}

EasyMile EZ10 12-Passenger Autonomous Vehicle (December 2016 Demonstration, Tampa, Florida)

\section{Implications of Automation Levels on Demand for Transit}

How automation will impact travel demand and the transportation infrastructure will depend on the degree of automation and the rate at which autonomous vehicles are introduced into the market. Automation Levels 0 through 4 will require a driver to be present in a vehicle. Level 4, which relieves the human driver of the task of constantly monitoring the driving environment, will change the experience of driving. Level 5 , as defined by USDOT and SAE, will open up entirely new categories of travel, with non-drivers able to make individual trips and vehicles able to shuttle empty as needed.

\section{Changing the Value of In-Vehicle Travel Time}

Vehicle automation will allow a human driver to spend a large portion of in-vehicle time productively engaged in other activities. The in-vehicle experience becomes more like that of a transit passenger. Evidence to support that hypothesis can be found by examining the direct elasticities of in-vehicle time for drivers and transit passengers. Zhang and Timmermans (2010) reported that information communication technologies (ICTs) made multitasking common among public transportation users, and that travel time elasticity was positively affected by the ability to undertake some tasks while riding in public transportation. Litman reported on travel time elasticities obtained from travel surveys in Portland, Oregon. The Portland data showed that in the morning peak, direct demand travel time elasticity for transit users was $57 \%$ of the comparable direct demand elasticity for auto drivers; in the evening peak, travel time elasticity for transit users was only $26 \%$ of the comparable elasticity for auto drivers 
(Litman 2017). The implication is that transit passengers are far less sensitive to changes in travel time than are auto drivers, possibly because they can engage in other productive activities while in motion.

\section{Impacts on Driving}

Level 3 automation allows a driver to do tasks that would currently lead to distracted driving, such as texting and talking on the phone or to passengers. Vehicles may be equipped to provide both video and audio infotainment to vehicle occupants including the driver. The net result will likely be that time spent in the driver's seat could be used to participate in leisure time or vocational activities that require higher levels of concentration such as reading, viewing video images, writing, and speaking. The frustration, stress, and boredom of being caught in stop-and-go traffic will be considerably lessened. Another Level 3 feature already being tested is autonomous valet parking. The driver gets out and the car proceeds at low speed to a parking space. Later, the driver summons the car from the parking space using an app on his or her smartphone. Vehicles equipped with this level of automation can be expected to encourage longer trips and more travel during peak periods.

Level 4 vehicles could be configured to allow even more freedom for the driver, such as the ability to move about in the cabin and engage in activities such as sleeping, grooming, preparing and eating a meal, or working out.

Fully autonomous vehicles, Level 5 , will not require a licensed driver to be present in the vehicle, opening a number of unprecedented possibilities for new trip making. Vehicles may be able to perform certain types of trips without any human occupants. Repositioning, or deadheading trips, which are common aspects of public transit and truck operations, would become feasible for personal autos. For example, one family member could use a vehicle for a commute trip and send the vehicle home for use by another family member. After dropping off a passenger, a vehicle could be dispatched to a remote parking or staging area to avoid parking charges in areas with limited parking availability and/or high costs. Vehicle interiors will combine elements of automotive design with more comfortable accommodations. The autonomous vehicle could become a mobile extension of stationary living space.

The ability of Level 5 vehicles to reposition themselves also creates the potential for autonomous taxis. Uber and other Mobility on Demand providers are already making large investments to develop autonomy for their fleets. Once the need to pay a driver goes away, the cost of a taxi ride can be reduced significantly, potentially becoming less than the cost of a similar trip on transit. In many areas, the convenience of on-demand autonomous taxi service will obviate the need to own a car.

\section{Changing Mobility and Demand}

Transit riders generally fall into two categories, captive and choice. Captive riders cannot drive or do not have access to a car. Choice riders generally do have access to cars, but choose transit when it can offer a faster, cheaper, or more convenient trip. Choice riders can avoid congestion, use time on transit to read, work, or sleep, and can avoid parking costs and hassles at their destinations. 
Autonomous vehicles will offer mobility to those transit captives who cannot drive, and, in conjunction with carsharing, offer mobility to those who do not have ready access to a car. For choice riders, self-driving cars can offer amenities similar to those of transit in terms of how travel time is used-reading, sleeping, or working. According to studies, autonomous cars could double highway capacity. Couple that with the ability to self-park, and the transit advantage could melt away. Therefore, the impact on many transit systems will be huge.

\section{Adapting to and Benefitting from Autonomous Operation}

To meet the challenges posed by autonomous vehicle technology, the transit industry must adapt both technologically and institutionally. The transit industry and government need to accelerate research and deployment of autonomous driving systems on transit buses. Compared with autos and trucks, transit's total of about 100,000 buses and paratransit vehicles is a niche market. Most bus Original Equipment Manufacturers act as systems integrators but do not have the expertise or financial incentive to research and develop autonomous driving systems. Transit agencies will need to push for assistance from the Federal Transit Administration (FTA), state, and local governments to sponsor and fund the research and development.

Three specific areas of autonomous driving have the greatest potential to benefit the transit industry: autonomous collision avoidance and emergency braking, autonomous systems to enable bus platooning, and autonomous driving technology to improve service to disabled passengers. These autonomous driving systems are not "pie in the sky" notions, but have been successfully demonstrated in pilot projects.

\section{Collision Avoidance and Emergency Braking}

Autonomous collision avoidance systems can produce significant benefits for the transit industry. Data from FTA's National Transit Database (NTD) show that buses and vanpools have been involved in 85,391 collisions, experienced 1,340 fatalities and 201,382 injuries between 2002 and 2014, and created expenditures for casualty and liability expenses of $\$ 5.7$ billion between 2002 and 2013 (Lutin et al. 2016).

The average annual cost per transit bus for casualty and liability expenses is about $\$ 6,600$. A recent study conducted by the Washington State Transit Insurance Pool showed that $65 \%$ of $\$ 53$ million in bus claims incurred over 13 years could have been prevented by using Autonomous Collision Avoidance and Autonomous Emergency Braking systems, resulting in significant reductions in collisions, fatalities, injuries, and insurance costs (Spears et al. 2017).

\section{Steering and Lane Keeping}

Autonomous driver assistance systems have the potential to improve the capacity and reliability of bus service. Autonomous steering control has been successfully demonstrated to allow buses to operate safely and reliably on narrow freeway shoulders and achieve travel time savings and lower operating costs than building light rail in the corridor. Figure 3 shows a Minnesota Valley Transit bus operating in a narrow shoulder on 1-35W, which was part of 
a pilot project testing the technology (Shankwitz 2015). Buses were equipped with sensors and lateral guidance controls that autonomously kept them centered in the narrow shoulder.

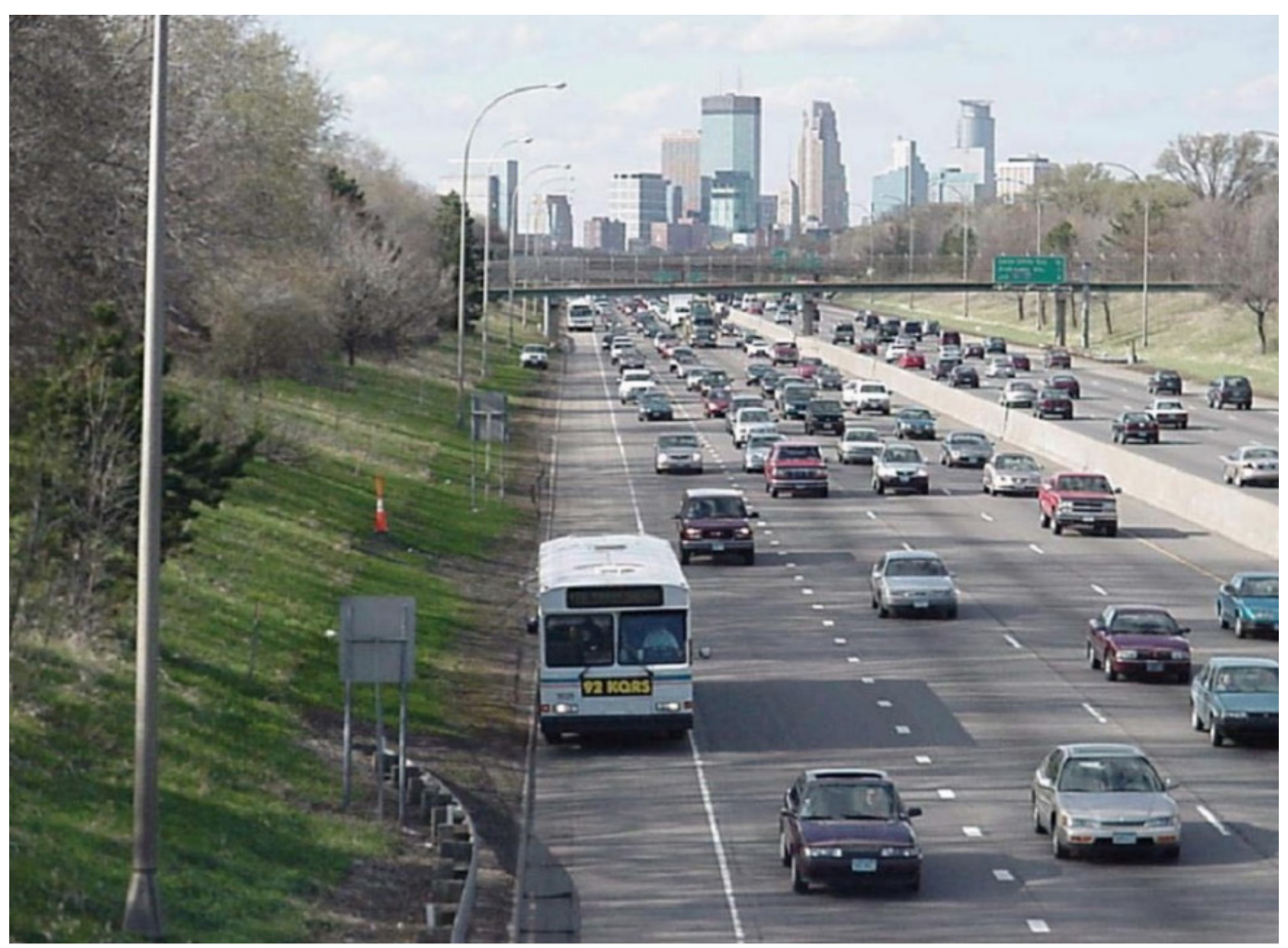

\section{FIGURE 3.}

Minnesota Valley Transit Bus on Shoulder System

\section{Bus Platooning}

Level 3 autonomous driving technology includes Cooperative Adaptive Cruise Control (CACC), which has the potential to increase capacity by enabling buses to operate at close headways, called platooning. CACC can produce dramatic increases in highway capacity, from 103\% to $273 \%$ (Vander Werf et al. 2002; Tientrakool et al. 2011). Drivers normally maintain sufficient separation from the preceding vehicle to allow them to safely stop if the vehicle ahead suddenly decelerates. CACC will sense speed changes and react far more quickly than a human driver. Consequently, platooning can decrease the distance and time interval between vehicles following one another in a lane. Lutin and Kornhauser (2014) showed that CACC could increase capacity on the contra-flow Exclusive Bus Lane (XBL) into Manhattan (shown in Figure 4) by 480 buses per hour, which would equal the capacity of a new commuter rail tunnel. 


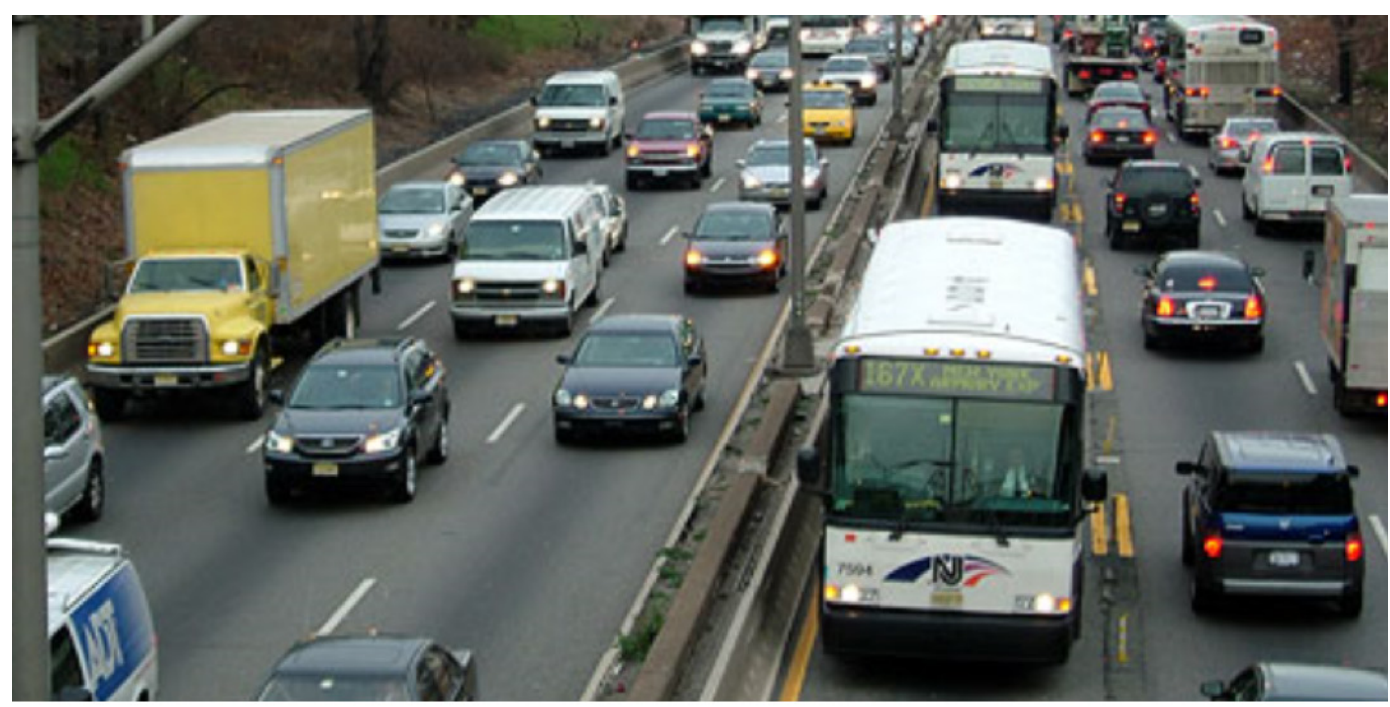

\section{FIGURE 4.}

Contra-Flow Exclusive Bus Lane into Manhattan (The Port Authority of New York \& New Jersey)

\section{Improved Service to Disabled Passengers}

One of the greatest benefits of driverless transit would be improved service to disabled passengers. Paratransit service for disabled individuals is often inconvenient, unreliable, and expensive. Disabled passengers often need to reserve a trip 24 hours prior to departure and they are told that their pickup may occur any time during a 2-hour window. The average operating cost per transit passenger trip in 2014 was $\$ 3.68$. Thirty-nine percent of that cost was covered by fares. In comparison, the average cost of a paratransit trip to serve a disabled passenger was almost 10 times more expensive, $\$ 34.43$, and only $8 \%$ of that was covered by fares (Lutin 2016).

Applying autonomous driving technology to paratransit service could dramatically improve service and reduce costs. There are, however, numerous challenges to overcome. The needs of mobility impaired individuals must be considered in the design of autonomous vehicles. In particular, robotic assistance will be needed to facilitate boarding, alighting, and onboard device securement. The ability to remotely monitor and communicate with disabled passengers also will be necessary.

\section{Precision Docking for Buses}

Boarding and alighting from transit buses can be a daunting challenge for mobility impaired individuals. "High" bus floor levels can be approximately 35 inches $(89 \mathrm{~cm})$ above street level and require use of a lift, and "low" bus floors can be 7.5-15.0 inches $(19-38 \mathrm{~cm})$ above street level depending on the availability of a "kneeling" suspension (U.S. Access Board 2017). Low floor buses generally have a deployable ramp for use by mobility impaired passengers. Both lifts and ramps take time to deploy. Lifts can be unreliable and a frequent cause of passenger injuries. Level boarding, in which the bus floor is level with the bus stop, is by far preferable for mobility impaired passengers and speeds boarding and alighting for all passengers. However, to 
comply with accessibility regulations for level boarding of light rail vehicles (which would apply to level boarding for buses as well), the horizontal gap between the vehicle and the platform edge must be no more than 4 inches $(10 \mathrm{~cm}$ ) (U.S. Access Board 2017). That gap is difficult to maintain with manual driving.

Lane Transit District in Eugene, Oregon, conducted a test that demonstrated the feasibility of autonomous precision docking on its Emerald Express (EmX) Bus Rapid Transit (BRT) line. For an FTA-sponsored pilot project, Gregg and Pessaro (2016) evaluated the Vehicle Assist and Automation (VAA) system on a 60 -foot (18-m) articulated bus equipped with a lateral guidance system that followed a trail of magnets embedded in the pavement. The magnetic guidance system consistently achieved horizontal gap standard deviations less than 0.76 inch $(1.94 \mathrm{~cm})$ from the target gap of 1.6 inches $(4.0 \mathrm{~cm})$. With the VAA guidance disabled, maximum standard deviation reached 4.4 inches $(11.08 \mathrm{~cm})$. Figure 5 illustrates the precision docking achieved by the VAA pilot.

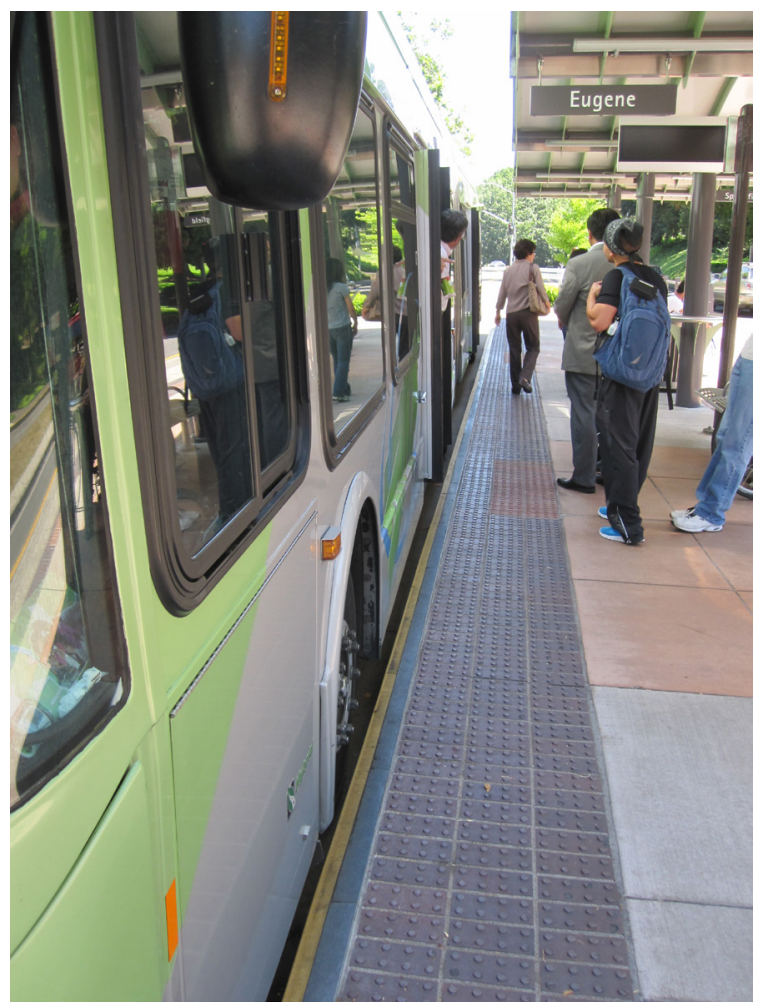

\section{FIGURE 5.}

Emerald Express Precision Docking, Eugene, Oregon (Gregg and Pessaro 2016)

\section{Autonomous BRT as an Alternative to Light Rail}

The net result of combining autonomous platooning with precision docking will produce a BRT-type service that can offer the same capacity and service as rail transit with significantly less cost. Cities considering whether to enter FTA's New Starts process for light rail transit (LRT) or streetcars should consider that autonomous driving may make BRT a more viable option. 
Rail transit will still offer advantages over autonomous BRT in a several situations. For example, where light rail systems already exist, it may make sense to use LRT for system extensions to avoid the need to transfer between modes and to achieve economies of scale. The need to overcome geographical barriers to major employment concentrations, such as bridging over or tunneling under rivers, constitute situations in which rail's superlative capacity may be a more cost-effective and efficient choice.

\section{Conclusion}

Ultimately transit will be operating alongside and competing with autonomous shared ride vehicles. On August 22, 2017, Sherif Marakby, vice president of Autonomous Vehicles and Electrification, articulated Ford Motor Company's intentions to enter the autonomous ridesharing market:

Ride sharing and hailing is on the rise, and shopping at malls is giving way to buying online, which is increasing package delivery services. Therefore, we're building a business to capitalize on both of these trends. We plan to develop and manufacture self-driving vehicles at scale, deployed in cooperation with multiple partners, and with a customer experience based on human-centered design principles. (Marakby 2016)

As the auto industry moves closer to marketing autonomous vehicles, the transit industry must become more engaged and make its voice heard by government and vehicle manufacturers. The transit industry's response to the introduction of autonomous driving should be to (1) promote shared-use taxis as a replacement for transit on many bus routes and for service to persons with disabilities; (2) concentrate transit resources in corridors where more auto traffic and parking will be too costly and too congested, and where transit can increase the people-carrying capacity of a lane beyond that of a general traffic lane; (3) exit markets where transit load factors are too low to justify operating a transit vehicle; and (4) focus attention on land use-work with partners to create transit-oriented development that limits the need for driving and where trip-end density will provide enough riders for both transit and autonomous shared-taxi services.

\section{References}

CityMobil2. 2015. Cities Demonstrating Automated Road Passenger Transport. Retrieved from http://www.citymobil2.eu/en/.

CityMobil2. 2017. Demonstration, Trikala, Greece. Retrieved from https://www.youtube.com/ watch?v=pLsmsTj393o.

Gregg, R. and B. Pessaro. 2016. Vehicle Assist and Automation (VAA) Demonstration Evaluation Report. FTA Report No. 0093, National Bus Rapid Transit Institute, Center for Urban Transportation Research, University of South Florida. https://www.transit.dot.gov/sites/ fta.dot.gov/files/docs/FTA_Report_No._0093.pdf. 
Juliussen, E., and J. Carlson. 2014. Emerging Technologies: Autonomous Cars - Not If, But When. IHS Automotive. http://press.ihs.com/press-release/automotive/self-driving-cars-movingindustrys-drivers-seat.

Litman, T. 2017. Understanding Transport Demands and Elasticities: How Prices and Other Factors Affect Travel Behavior. Victoria Transport Policy Institute. http://www.vtpi.org/ elasticities.pdf.

Lutin, J. M. 2016. "The Implications of Automated Vehicles for the Public Transit Industry." Presentation to I-95 Corridor Coalition. http://i95coalition.org/ wp-content/uploads/2016/03/LUTIN-Panel-5nsofAutomatedVehiclesforTransitforl95CorridorCoalition.pdf? $\times 70560$

Lutin, J. M., and A. L. Kornhauser. 2014. Application of Autonomous Driving Technology to Transit: Functional Capabilities for Safety and Capacity. TRB Paper Number 14-0207, 93rd Annual Meeting of the Transportation Research Board, Washington, DC.

Lutin, J. M., A. L. Kornhauser, J. Spears, and L. F. Sanders. 2016. A Research Roadmap for Substantially Improving Safety for Transit Buses through Autonomous Braking Assistance for Operators. TRB Paper Number 16-1246, 95th Annual Meeting of the Transportation Research Board, Washington, DC.

Marakby, S. 2017. "Building a Business Enabled by Self-Driving Technology." Self-Driven Blog, August 22, Ford Motor Company. Retrieved from https://medium.com/self-driven/ building-a-business-enabled-by-self-driving-technology-875ca374ab8a.

Shankwitz, C. 2015. "Minnesota Bus on Shoulder System (BoSS): Automating Public Mass Transit in the Connected and Automated Era." Presentation at the Transportation Research Board Annual Meeting.

Spears, J., J. M. Lutin, Y. Wang, R. Ke, and S. M. Clancy. 2017. Active Safety-Collision Warning Pilot in Washington State. Final Report, Transit IDEA Project 82. Washington, DC: Transportation Research Board. http://onlinepubs.trb.org/onlinepubs/IDEA/FinalReports/ Transit/Transit82.pdf.

Tesla. 2017. "Full Self-Driving Capability." https://www.tesla.com/autopilot.

The Port Authority of New York \& New Jersey. 2017. Retrieved from http://www.panynj.gov/ bridges-tunnels/lincoln-tunnel-xbl.html.

Thrun, S. 2010. "What we're driving at." Official Blog, October 9. http://googleblog.blogspot. com/2010/10/what-were-driving-at.html.

Tientrakool, P., Y. C. Ho, and N. Maxemchuk. 2011. Highway Capacity Benefits from Using Vehicle-to-Vehicle Communication and Sensors for Collision Avoidance. New York, NY: Columbia University, Department of Electrical Engineering.

U.S. Access Board. 2017. "Subpart D -- Light Rail Vehicles and Systems." Retrieved from https://www.access-board.gov/guidelines-and-standards/transportation/vehicles/ technical-assistance-manuals-on-adaag-for-transportation-vehicles/subpart-b-buses-vansand-systems. 
USDOT. 2016. Federal Automated Vehicles Policy: Accelerating the Next Revolution In Roadway Safety. U.S. Department of Transportation, National Highway Traffic Safety Administration. https://www.transportation.gov/sites/dot.gov/files/docs/AV\%20policy\%20 guidance\%20PDF.pdf.

Vander Werf, J., S. Shladover, M. Miller, and N. Kourjanskaia. 2002. "Effects of Adaptive Cruise Control Systems on Highway Traffic Flow Capacity." Transportation Research Record: Journal of the Transportation Research Board, 1800: 78-84. Washington, DC: Transportation Research Board of the National Academies. doi: 10.3141/1800-10.

Zhang, J., and H. Timmermans. 2010. "Scobit-Based Panel Analysis of Multitasking Behavior of Public Transport Users." Transportation Research Record: Journal of the Transportation Research Board, 2157: 46-53. Washington, DC: Transportation Research Board of the National Academies. doi: 10.3141/2157-06.

\section{About the Author}

Jerome M. Lutin, PH.D., P.E. (jerome.lutin@verizon.net) is an independent consultant engaged in research and planning for automated vehicles. He has written and lectured extensively on the implications of automated vehicles for the transit industry. His career includes 50 years of professional experience in transportation planning and engineering. Dr. Lutin retired from positions as distinguished research professor at New Jersey Institute of Technology and as senior director of Statewide and Regional Planning at New Jersey Transit, where he planned new light rail lines and the Newark International Airport rail station. A fellow of the Institute of Transportation Engineers, he has been involved in the development and teaching of Intelligent Transportation Systems (ITS) standards for the transit industry. He holds a master's degree in Architecture and Urban Planning and a Ph.D. in Urban Planning, both from Princeton University. He is a licensed professional engineer, a certified planner, and a U.S. Air Force veteran. 